J. Lake Sci.(湖泊科学), 2020, 32(3): 701-712

DOI 10. 18307/2020. 0310

(c) 2020 by Journal of Lake Sciences

\title{
云南程海和阳宗海季节性分层及其消退对冬季水华的潜在影响”
}

\author{
周起超 ${ }^{1,2 * *}$,杨 炫 $^{1}$, 王玮璐 ${ }^{2}$, 董 静 $^{3}$, 黄立成 ${ }^{2}$,秦 江 $^{2}$ \\ ( 1 : 云南大学生态与环境学院高原湖泊生态与治理研究院, 昆明 650500) \\ (2:云南省生态环境科学研究院云南省高原湖泊流域污染过程与管理重点实验室,昆明 650034) \\ (3:河南师范大学水产学院,新乡 453007)
}

\begin{abstract}
摘 要: 基于 2014 年 10 月 -2016 年 7 月在云南程海和阳宗海开展了 4 个季度(秋季, 10 月; 冬季, 1 月; 春季, 4 月; 夏季, 7 月) 的调查, 研究了两个湖泊的水体分层特征, 探讨了热力分层及其变化与其他环境因子对浮游植物生物量的潜在影 响, 结果显示: 程海和阳宗海水体分层的特征均为冬季混合、春季形成分层、夏秋季分层稳定, 两湖均属暖单次混合型湖 泊; 程海分层期温跃层的平均深度 (顶界) 、厚度和强度分别为 $17.70 \pm 3.89 \mathrm{~m} 、 5.54 \pm 4.44 \mathrm{~m}$ 和 $0.67 \pm 0.43^{\circ} \mathrm{C} / \mathrm{m}$, 阳宗海的分 别为 $12.53 \pm 3.35 \mathrm{~m} 、 8.25 \pm 4.85 \mathrm{~m}$ 和 $0.53 \pm 0.43^{\circ} \mathrm{C} / \mathrm{m}$. 在热力分层稳定期, 两湖底层达到缺氧甚至厌氧状态, 底层的电导率 总体较表层高. 调查期间, 两个湖泊水柱表层浮游植物生物量 (以叶绿素 $a$ 浓度表征) 均在冬季出现峰值, 程海和阳宗海 的分别为 $19.22 \pm 11.08$ 和 $45.82 \pm 9.41 \mu \mathrm{g} / \mathrm{L}$; 进一步分析发现, 热力分层的消退可能是导致水体表层无机营养盐升高(底 层供给) 的重要原因, 加之适宜的光热条件可诱导两湖冬季水华的发生; 在其他季节转化期间, 浮游植物生物量变化的主 要影响因子亦具有一定的共性及湖泊与季节异质性.
\end{abstract}

关键词: 温跃层;溶解氧;营养盐;浮游植物;冬季水华;云南高原;程海;阳宗海

\section{Seasonal vertical stratification and the potential impacts of its fading on algal blooms in winter: Cases of Lake Chenghai and Lake Yangzonghai, Yunnan Plateau*}

\author{
ZHOU Qichao ${ }^{1,2 * *}$, YANG Xuan ${ }^{1}$, WANG Weilu ${ }^{2}$, DONG Jing ${ }^{3}$, HUANG Licheng ${ }^{2} \&$ QIN Jiang ${ }^{2}$ \\ (1: Institute for Ecological Research and Pollution Control of Plateau Lakes, School of Ecology and Environmental Sciences, \\ Yunnan University, Kunming 650500, P.R.China) \\ (2: Yunnan Key Laboratory of Pollution Process and Management of Plateau Lake-Watershed, Yunnan Research Academy of \\ Eco-environmental Sciences, Kunming 650034, P.R.China) \\ (3: College of Fisheries, Henan Normal University, Xinxiang 453007, P.R. China)
}

Abstract: The thermal stratification and its potential impacts on the phytoplankton biomass were studied through the four seasonal field investigations (October 2014-July 2016) in Lake Chenghai and Lake Yangzonghai, two mesotrophic deep lakes on the Yunnan Plateau, southwest China. The results revealed that these two lakes are both warm monomictic lakes, where the vertical stratification was occurred in spring, stabilized in summer and autumn, and disappeared in winter. The mean values of thermocline depth (the upper boundary), thickness and strength during the stratification periods (spring, summer and autumn) were 17.70 \pm 3.89 $\mathrm{m}, 5.54 \pm 4.44 \mathrm{~m}$ and $0.67 \pm 0.43^{\circ} \mathrm{C} / \mathrm{m}$ in Lake Chenghai and were $12.53 \pm 3.35 \mathrm{~m}, 8.25 \pm 4.85 \mathrm{~m}$ and $0.53 \pm 0.43^{\circ} \mathrm{C} / \mathrm{m}$ in Lake Yangzonghai, respectively. During the stabilized thermal stratification periods, the dissolved oxygen in the bottom of the water column reached less than $3 \mathrm{mg} / \mathrm{L}$ even $1 \mathrm{mg} / \mathrm{L}$, and the specific conductance in the bottom was generally larger than that in the surface water column. In these two lakes, the maximum values of the seasonal-average algal biomass ( represented by chlorophyll- $a$ concentration) were both in winter, which was $19.22 \pm 11.08 \mu \mathrm{g} / \mathrm{L}$ in Lake Chenghai and $45.82 \pm 9.41 \mu \mathrm{g} / \mathrm{L}$ in Lake Yangzonghai. Moreover, the fading of thermal stratification may be an important factor that increases the inorganic nutrients in the surface of water

* 2019-10-07 收稿;2019-11-04 收修改稿.

国家重点研发计划项目(2017YFA0605202)、国家自然科学基金项目 (41601208，51609229)和云南省高原湖泊流 域污染过程与管理重点实验室项目联合资助.

** 通信作者;E-mail: qchzhou@ynu.edu.cn. 
column (from the bottom of water column). Thereafter, higher nutrients combined with suitable light conditions and water temperature could promote the occurrence of algal blooms in winter. Besides a certain similarity, the major influencing factors of seasonal phytoplankton biomass also had inter-lake and seasonal heterogeneity during the other periods of season changes.

Keywords: Thermocline; dissolved oxygen; nutrients; phytoplankton; algal blooms in winter; Yunnan Plateau; Lake Chenghai; Lake Yangzonghai

热力分层及其季节性变化是深水湖泊 (水库) 的一个重要特征, 湖泊热力分层及其循环周期与稳定性对 水体溶解氧 $(\mathrm{DO})^{[1]}$ 、沉积物微生物过程 ${ }^{[2]}$ 、营养盐分布及其可利用性 ${ }^{[3-4]}$, 以及浮游植物垂直分布与群落结 构 ${ }^{[3,5-6]}$ 等有着重要的影响, 进而影响湖泊水质、初级生产力、食物网结构等, 故对热力分层特征的深人了解 是实现对深水湖泊生态环境保护的重要前提. 目前, 国内外关于湖库热力分层的研究已有诸多报道, 如针对 Lake Müggelsee $e^{[7]}$ 、Lake Caldonazzo ${ }^{[8]}$ 、千岛湖 ${ }^{[9-10]}$ 、天山天池 ${ }^{[11]}$ 、纳木错 ${ }^{[12]}$ 、天目湖 ${ }^{[13]}$ 及空间大尺度的研 究 ${ }^{[14-15]}$ 等. 云南高原是我国云贵高原湖区的重要组成部分, 由于缺乏相关基础性工作和基础数据的积累, 目 前关于其湖泊热力分层的研究仅局限于对抚仙湖 ${ }^{[16-17]}$ 、泸沽湖 ${ }^{[18-19]} 、$ 、洱海 ${ }^{[20]}$ 、程海 ${ }^{[21]}$ 和阳宗海 ${ }^{[22]}$ 等的零星 报道.

藻类 (浮游植物) 水华是诸多水体面临的严峻环境问题, 表层水温常是浮游植物生物量季节变化 (夏秋 季高、冬春季低) 的主控因素之一 ${ }^{[23]}$; 稳定的热力分层被认为阻碍了水体上下层的物质交换, 有助于藻类水 华的暴发和维持 ${ }^{[24-25]}$, 如气候变暖导致的更强烈的热力分层被认为利于夏季温跃层附近粉红浮丝藻 ( Planktothrix rubescens) 水华的发生 ${ }^{[26]}$, 人工加深温跃层深度亦有利于湖上层的 P. rubescens 占优 ${ }^{[3]}$, 针对天目湖的 研究显示, 稳定的热力分层利于蓝藻门的繁殖 ${ }^{[13]}$. 然而, 浮游植物生物量的季节变化并不一定呈现 “夏秋季 高、冬春季低” 的趋势, 如云南程海浮游植物细胞密度、叶绿素 $a(\mathrm{Chl} . a)$ 浓度和初级生产力均会在冬季出现 另一次波峰 ${ }^{[27-28]}$, 根据文献记载 ${ }^{[29]}$ 及笔者 2015 年 1 月 19 日的现场观测均显示程海在冬季发生过藻类水华 (冬季水华, 本研究以浮游植物生物量一Chl. $a$ 浓度间接表征), 针对云南阳宗海的调查亦发现其冬季的 Chl. $a$ 浓度明显高于夏季 ${ }^{[30]}$, 但关于其发生机制仍不清楚.

因此,本研究基于 2014 年 10 月-2016 年 7 月对程海和阳宗海开展 4 个季度的调查, 在识别两个湖泊热 力分层、垂直剖面 DO 与电导率 (SpCond) 分布及水柱表层营养盐、浮游植物生物量季节变化及其影响因子 的基础上,重点探讨了两湖水体分层消退对冬季水华发生的潜在影响.

\section{1 材料与方法}

\section{1 研究区域概况}

程海 ( $26^{\circ} 27^{\prime} \sim 26^{\circ} 38^{\prime} \mathrm{N}, 100^{\circ} 38^{\prime} \sim 100^{\circ} 41^{\prime} \mathrm{E}$; 图 1a) 地处云南省丽江市永胜县中部、金沙江河谷地带, 约 1690 年前后开始演变为内陆封闭型深水湖泊, 水位 $1503.0 \mathrm{~m}$, 面积 $77.22 \mathrm{~km}^{2}$, 平均水深 $25.7 \mathrm{~m}$, 最大水深 $35.1 \mathrm{~m}$, 蓄水量 $19.87 \times 10^{8} \mathrm{~m}^{3}$, 流域面积 $228.9 \mathrm{~km}^{2}$. 阳宗海 $\left(24^{\circ} 51^{\prime} \sim 24^{\circ} 58^{\prime} \mathrm{N}, 102^{\circ} 58^{\prime} \sim 103^{\circ} 01^{\prime} \mathrm{E}\right.$; 图 $\left.1 \mathrm{~b}\right)$ 地处 云南省昆明市东南, 水位 $1770.75 \mathrm{~m}$, 面积 $31.68 \mathrm{~km}^{2}$, 平均水深 $19.5 \mathrm{~m}$, 最大水深 $30.0 \mathrm{~m}$, 蓄水量 $6.17 \times 10^{8}$ $\mathrm{m}^{3}$, 流域面积 $192.0 \mathrm{~km}^{2}$. 程海和阳宗海均为云南九大高原湖泊之一、属构造断陷型中营养深水湖泊, 为亚热 带季风气候.

\section{2 样品采集与指标测定}

在程海布设 9 个点位(图 1a), 于 2014 年 10 月 22 日(秋季)和 2015 年 1 月 19 日 (冬季)、4月 10 日 (春 季)、7月 2 日(夏季)开展调查工作; 在阳宗海布设 6 个点位(图 1b), 于 2014 年 10 月 27 日-28 日 (秋季) 和 2015 年 1 月 8 日 (冬季)、 4 月 17 日 (春季) 及 2016 年 7 月 21 日 (夏季) 开展调查工作. 用多参数水质监测 仪 YSI-6600 (Xylem Inc., USA) 测定各点位水温 (WT)、DO、SpCond 的垂直剖面变化; 将温度垂直梯度大于 $0.2^{\circ} \mathrm{C} / \mathrm{m}$ 的水层界定为温跃层, 根据文献 [ 10]计算温跃层的顶界深度 (代表温跃层深度)、底界深度、厚度和 强度. 利用 PUV-2500 水下剖面辐射仪 (Biospherical Instruments Inc., USA) 测定 0 3.5 m 处光合有效辐射强 度的剖面变化, 据此计算真光层深度 ${ }^{[31]}$. 同时, 采集各点位水柱表层 (水下 $0.5 \mathrm{~m}$ ) 的水样, 用以测定其他参 数——总氮 $(\mathrm{TN})$ 、总磷 $(\mathrm{TP})$ 、氨氮 $\left(\mathrm{NH}_{3}-\mathrm{N}\right)$ 、硝酸盐氮 $\left(\mathrm{NO}_{3}^{-}-\mathrm{N}\right)$ 、溶解性活性磷 $(\mathrm{SRP})$ 和 Chl. $a$ 浓度 $($ 表征浮 游植物生物量), 其测定方法参照文献 [32]. 


\section{3 统计分析}

本研究所示的均值为平均值土标准差; 两独立样本 (Mann-Whitney U)、多独立样本 (Kruskal-Wallis H) 非 参数检验与 Spearman 相关性分析均由 SPSS Statistics 24.0 软件完成, $P<0.05$ 表示显著, $P<0.01$ 表示极显著.
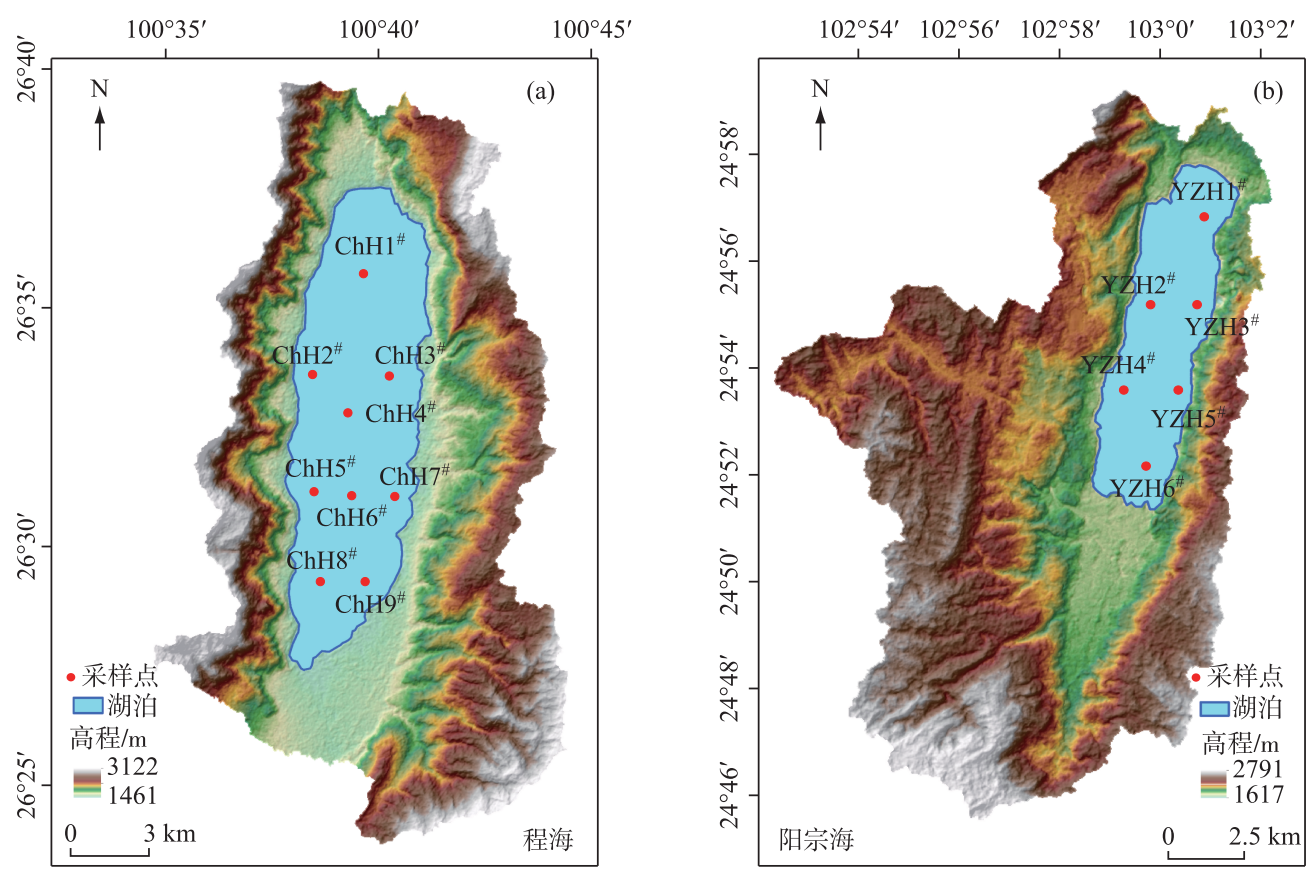

图 1 程海 (a) 和阳宗海 (b) 采样点位

Fig. 1 Sampling sites of Lake Chenghai(a) and Lake Yangzonghai(b)

\section{2 结果}

\section{1 两湖气温与降水量的季节变化}

根据国家气象信息中心 (http://data.cma.cn/) 资料(1981 年 1 月-2010 年 12 月), 程海附近永胜县 (台 站编号: 56652 ; 经纬度: $26.41^{\circ} \mathrm{N}, 100.45^{\circ} \mathrm{E}$; 海拔: $\left.2130.5 \mathrm{~m}\right) 1$ 月、4 月、7 月、10月的月平均气温分别为 6.4 、 $14.9 、 19.1$ 和 $14.5^{\circ} \mathrm{C}$, 月平均降水量分别为 $5.8 、 14.3 、 254$ 和 $73.7 \mathrm{~mm}$; 宾川县 (台站编号: 56752 ; 经纬度: $25.5^{\circ} \mathrm{N}$, $100.34^{\circ} \mathrm{E}$; 海拔: $\left.1438.7 \mathrm{~m}\right) 1$ 月、 4 月、7 月、10 月的月平均气温分别为 $10.5 、 20.2 、 23.9$ 和 $19.3^{\circ} \mathrm{C}$, 月平均降水 量分别为 $3.4 、 9.4 、 139.8$ 和 $50.1 \mathrm{~mm}$. 阳宗海附近宜良县 (台站编号: 56880 ; 经纬度: $24.55^{\circ} \mathrm{N}, 103.1^{\circ} \mathrm{E}$; 海拔: $1532.5 \mathrm{~m}) 1$ 月、 4 月、7 月、10 月的月平均气温分别为 $9.1 、 19.2 、 21.6$ 和 $17.2^{\circ} \mathrm{C}$, 月平均降水量分别为 16.7 、 $24.3 、 166.8$ 和 $76 \mathrm{~mm}$; 澄江县 (台站编号: 56873 ; 经纬度: $24.41^{\circ} \mathrm{N}, 102.55^{\circ} \mathrm{E}$; 海拔: $1796.3 \mathrm{~m}$ ) 1 月、4 月、7 月、 10 月的月平均气温分别为 $9.4 、 17.8 、 20.8$ 和 $16.6^{\circ} \mathrm{C}$, 月平均降水量分别为 $14.2 、 27.6 、 210.5$ 和 $80.6 \mathrm{~mm}$.

\section{2 两湖水温剖面与温跃层参数的季节变化}

程海秋、冬、春、夏四季的表层水温分别为 $22.96 \pm 0.25 、 14.33 \pm 0.12 、 16.70 \pm 0.23$ 和 $24.67 \pm 0.38^{\circ} \mathrm{C}$ ( 图 $2 \mathrm{a} \sim$ d), 阳宗海秋、冬、春、夏四季的表层水温分别为 $19.98 \pm 0.17 、 13.63 \pm 0.16 、 18.01 \pm 0.69$ 和 $23.43 \pm 0.33^{\circ} \mathrm{C}$ (图 $2 \mathrm{e} \sim \mathrm{h}$ ), 两湖间四季或分层季节的表层水温均无显著性差异 $(P>0.05)$; 除冬季外, 两个湖泊秋、春、夏三 季均有一定的热力分层, 同一季节各点位的温跃层分布状况具有一定的异质性 (图 2 , 表 1). 就温跃层的深 度、厚度和强度而言 (表 1$)$, 程海春季温跃层深度显著大于夏季 $(P<0.01)$ 和秋季 $(P<0.05)$, 夏、秋季温跃层 的深度、厚度和强度均无显著性差异 $(P>0.05)$, 秋季的厚度和强度显著大于春季 $(P<0.01)$, 夏季的厚度略 大于春季 $(P=0.07)$ 、强度显著大于春季 $(P<0.01)$; 阳宗海夏季温跃层深度显著小于春季 $(P<0.01)$ 和秋季 
$(P<0.05)$ 、春秋季间无显著性差异 $(P>0.05)$, 秋季和春季的温跃层厚度和强度均无显著性差异 $(P>0.05)$, 夏季的厚度显著大于秋季 $(P<0.05)$ 和春季 $(P<0.01)$, 夏季的强度与春季、秋季均无显著性差异 $(P>0.05)$. 就程海和阳宗海间温跃层参数比较而言 (表 1$)$, 程海的温跃层深度 $(P<0.01)$ 、底界深度 $(P<0.05)$ 均显著大 于阳宗海, 两湖温跃层厚度和强度则无显著差异 $(P>0.05)$.
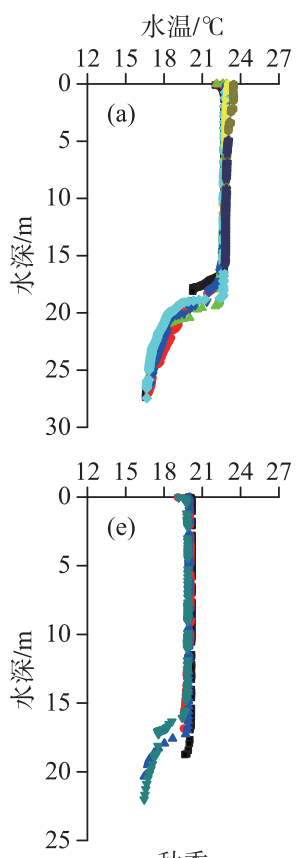

秋季
水温 $/{ }^{\circ} \mathrm{C}$
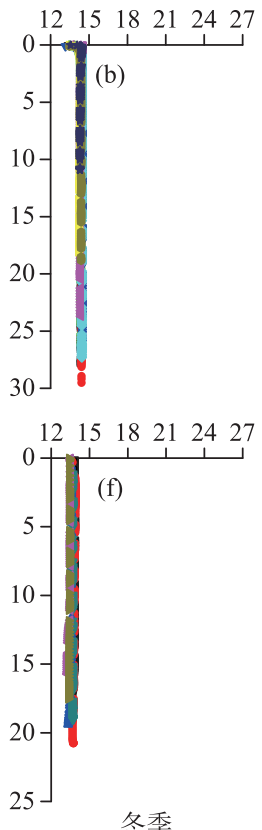

水温 $/{ }^{\circ} \mathrm{C}$
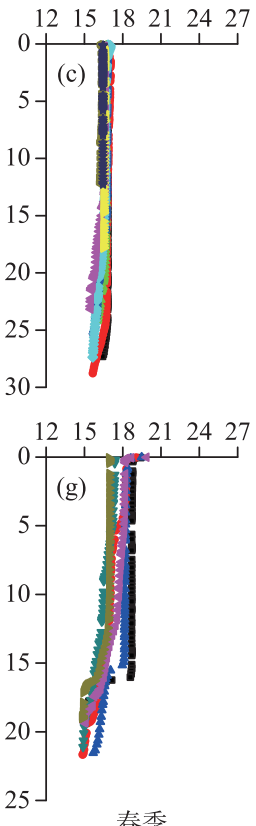

水温 $/{ }^{\circ} \mathrm{C}$
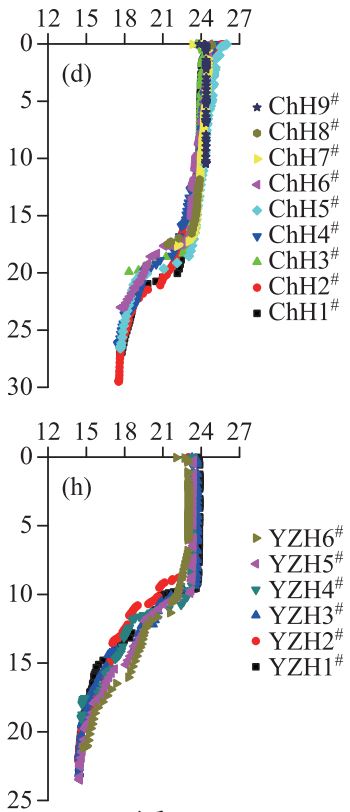

夏季

图 2 程海 $(\mathrm{a} \sim \mathrm{d})$ 和阳宗海 $(\mathrm{e} \sim \mathrm{h})$ 水温剖面的季节变化

Fig.2 Seasonality in vertical profile of water temperature in Lake Chenghai $(a-d)$ and Lake Yangzonghai $(e-h)$

表 1 程海和阳宗海温跃层参数的季节变化

Tab.1 Seasonality in some parameters of thermocline in Lake Chenghai and Lake Yangzonghai

\begin{tabular}{|c|c|c|c|c|c|}
\hline \multirow{2}{*}{ 湖泊 } & \multirow{2}{*}{ 季节 } & \multicolumn{4}{|c|}{ 温跃层参数( 均值土标准差) } \\
\hline & & 顶界/m & 底界/m & 厚度/m & 强度/ $\left({ }^{\circ} \mathrm{C} / \mathrm{m}\right)$ \\
\hline \multirow[t]{5}{*}{ 程海 } & 秋 ${ }^{\mathrm{a}}$ & $17.38 \pm 1.39$ & $24.43 \pm 1.31$ & $7.05 \pm 2.49$ & $0.86 \pm 0.29$ \\
\hline & 冬 & - & - & - & - \\
\hline & 春 $^{\mathrm{b}}$ & $21.52 \pm 3.81$ & $23.44 \pm 3.67$ & $1.92 \pm 1.54$ & $0.23 \pm 0.08$ \\
\hline & 夏 ${ }^{\mathrm{C}}$ & $15.03 \pm 2.58$ & $22.33 \pm 3.49$ & $7.30 \pm 5.39$ & $0.87 \pm 0.43$ \\
\hline & 总 ${ }^{d}$ & $17.70 \pm 3.89$ & $23.23 \pm 3.10$ & $5.54 \pm 4.44$ & $0.67 \pm 0.43$ \\
\hline \multirow[t]{5}{*}{ 阳宗海 } & 秋 ${ }^{e}$ & $16.11 \pm 1.16$ & $20.12 \pm 1.27$ & $4.01 \pm 2.23$ & $0.56 \pm 0.39$ \\
\hline & 冬 & - & - & - & - \\
\hline & 春 $^{\mathrm{b}}$ & $14.25 \pm 1.96$ & $19.41 \pm 1.87$ & $5.16 \pm 2.15$ & $0.58 \pm 0.63$ \\
\hline & 夏 ${ }^{\mathrm{b}}$ & $9.01 \pm 0.95$ & $22.48 \pm 1.80$ & $13.46 \pm 2.06$ & $0.47 \pm 0.24$ \\
\hline & 总 ${ }^{f}$ & $12.53 \pm 3.35$ & $20.78 \pm 2.18$ & $8.25 \pm 4.85$ & $0.53 \pm 0.43$ \\
\hline
\end{tabular}

${ }^{\mathrm{a}} N=5,{ }^{\mathrm{b}} N=6,{ }^{\mathrm{c}} N=8,{ }^{\mathrm{d}} N=19,{ }^{\mathrm{e}} N=3,{ }^{\mathrm{f}} N=15$.

进一步分析发现, 程海表层水温与温跃层深度呈显著负相关 $(r=-0.654, P<0.01, N=19)$, 与厚度 $(r=$ $0.493, P<0.05, N=19)$ 、强度 $(r=0.602, P<0.01, N=19)$ 呈显著正相关; 阳宗海表层水温与温跃层深度呈显 著负相关 $(r=-0.536, P<0.05, N=15)$, 与厚度呈显著正相关 $(r=0.568, P<0.05, N=15)$, 与温跃层强度无 
显著相关性 $(r=0.246, P=0.376, N=15)$. 真光层深度与温跃层参数的关系方面, 程海 $(N=19)$ 或阳宗海 $(N=15)$ 的真光层深度与温跃层深度、厚度和强度之间均未检出显著的相关性. 此外, 程海和阳宗海的平均 真光层深度分别为 $6.16 \pm 1.12 \mathrm{~m}(N=36)$ 和 $6.44 \pm 1.21 \mathrm{~m}(N=24)$, 两湖间四季或分层季节的真光层深度均无 显著性差异 $(P>0.05)$.

\section{3 两湖溶解氧浓度和电导率垂直分布的季节变化}

程海 DO 浓度垂直分布的季节变化如图 3a d 所示: 在秋、夏季形成氧跃层, 深水区达到缺氧状态 $(<3$ $\mathrm{mg} / \mathrm{L})$, 秋季深层水 DO 浓度甚至低于 $1 \mathrm{mg} / \mathrm{L}$; 春季, 形成氧跃层雉形, 深水区暂未出现缺氧; 冬季, DO 浓度 的垂直分布变化不明显. 阳宗海在秋、夏季形成氧跃层, 深水区达到缺氧状态 (图 $3 \mathrm{e} 、 \mathrm{~h}$ ) ; 冬季, DO 浓度的垂 直分布变化不明显 (图 3f); 春季, 形成氧跃层维形, 但深水区暂未出现缺氧现象 (图 3g). 程海和阳宗海 SpCond 垂直分布的季节变化如图 4a h 所示: 程海的 SpCond 明显高于阳宗海, 冬季两湖 SpCond 的垂直分布 相对均一, 春季两湖 SpCond 随水深增加有微弱的上升趋势; 秋、夏季, 两湖 SpCond 的垂直分布变化与 WT 剖 面基本呈反向趋势,但夏季程海的 SpCond 在温跃层升高后随着水深增加而降低直至稳定.
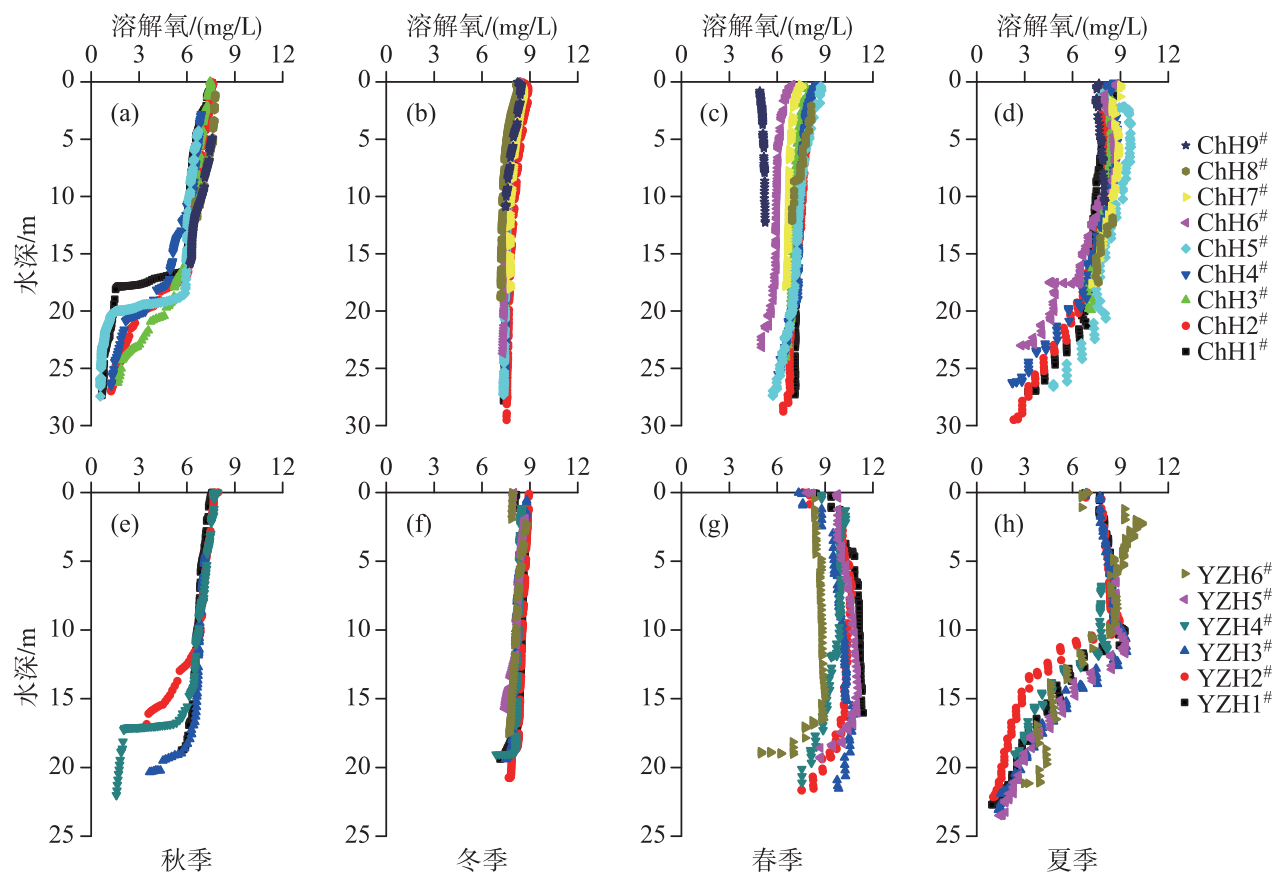

图 3 程海 $(\mathrm{a} \sim \mathrm{d})$ 和阳宗海 $(\mathrm{e} \sim \mathrm{h})$ 溶解氧浓度垂直剖面的季节变化

Fig.3 Seasonality in vertical profile of dissolved oxygen in Lake Chenghai $(a-d)$ and Lake Yangzonghai $(e-h)$

\section{4 两湖表层水体叶绿素 $a$ 和营养盐浓度的季节变化}

程海秋、冬、春、夏季的表层水体 Chl. $a$ 浓度分别为 $5.62 \pm 0.92 、 19.22 \pm 11.08 、 8.06 \pm 0.74$ 和 $12.52 \pm 4.70$ $\mu \mathrm{g} / \mathrm{L}($ 图 5a) , 冬季显著大于秋季 $(P<0.01)$ 和春季 $(P<0.05)$, 夏季显著大于春季和秋季 $(P<0.01)$, 冬季与夏 季无显著差异 $(P>0.05)$; 阳宗海秋、冬、春、夏季的表层水体 Chl. $a$ 浓度分别为 $17.64 \pm 0.78 、 45.82 \pm 9.41$ 、 $15.19 \pm 0.95$ 和 $18.27 \pm 1.32 \mu \mathrm{g} / \mathrm{L}$ ( 图 $5 \mathrm{~b})$, 冬季显著大于其他 3 个季节 $(P<0.01)$, 夏季显著大于春季 $(P<$ $0.01)$, 夏季与秋季无显著性差异 $(P>0.05)$. 程海秋、冬、春、夏季的表层水体 Chl. $a$ 浓度的中位数分别为 $5.28 、 14.39 、 8.07$ 和 $12.57 \mu \mathrm{g} / \mathrm{L}$, 阳宗海的分别为 $17.55 、 43.35 、 15.14$ 和 $18.26 \mu \mathrm{g} / \mathrm{L}$, 两湖冬季的值均最高 (图 5 ); 两湖冬季表层水体 Chl. $a$ 浓度的变化范围较其他季节更大 (图 5).

营养盐的季节差异方面, 若以无热力分层的冬季为参照, 程海冬季的 $\mathrm{TN} 、 \mathrm{NH}_{3}-\mathrm{N}$ 和 $\mathrm{NO}_{3}^{-}-\mathrm{N}$ 浓度显著高 于秋季, $\mathrm{TP}$ 和 $\mathrm{SRP}$ 浓度显著高于春季, $\mathrm{TP} 、 \mathrm{NH}_{3}-\mathrm{N}$ 和 $\mathrm{SRP}$ 浓度显著高于夏季, $\mathrm{NO}_{3}^{-}-\mathrm{N}$ 浓度显著低于夏季; 阳 


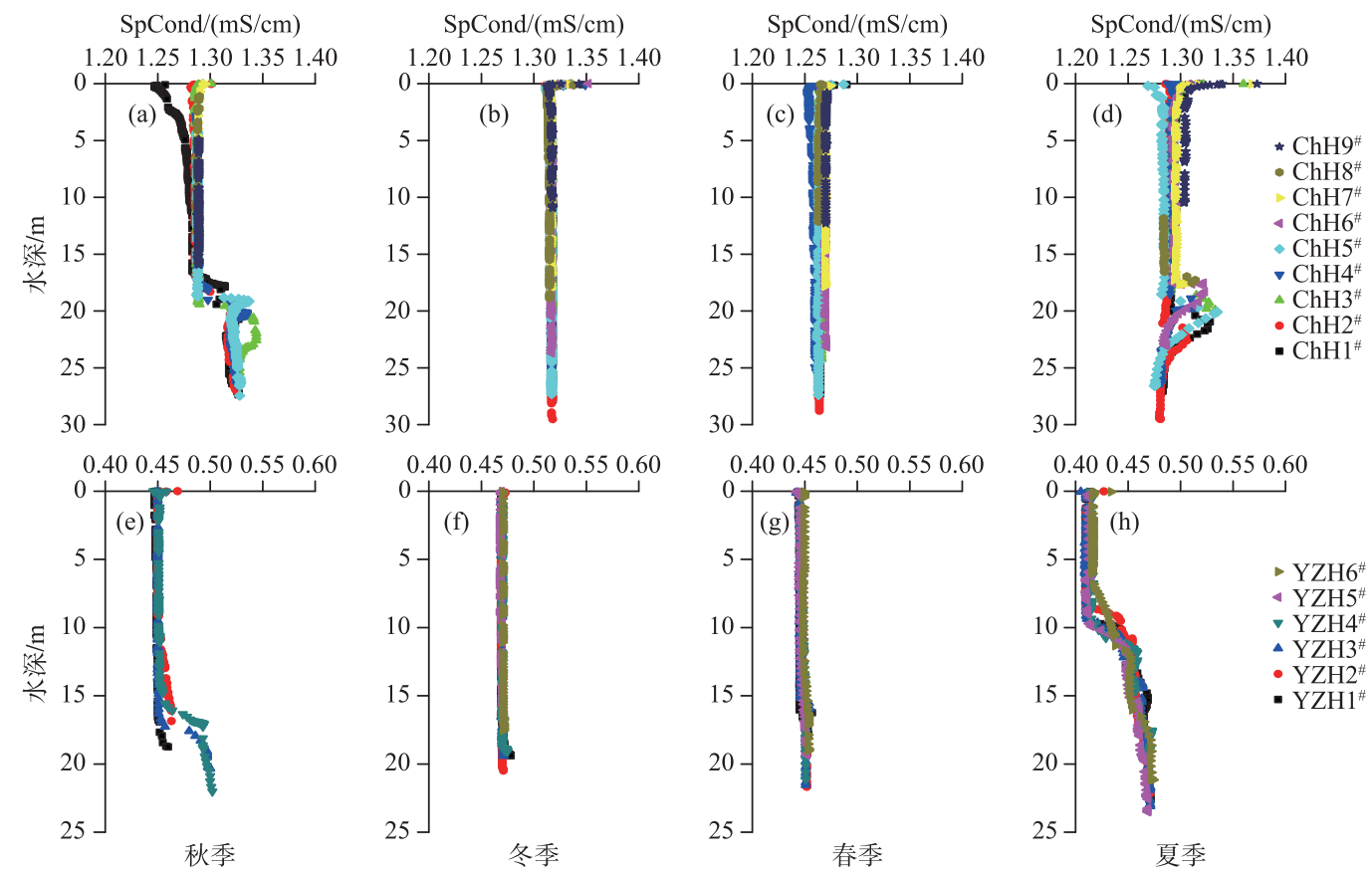

图 4 程海 $(\mathrm{a} \sim \mathrm{d})$ 和阳宗海 $(\mathrm{e} \sim \mathrm{h})$ 电导率垂直剖面的季节变化

Fig.4 Seasonality in vertical profile of SpCond in Lake Chenghai ( $a-d)$ and Lake Yangzonghai (e-h)
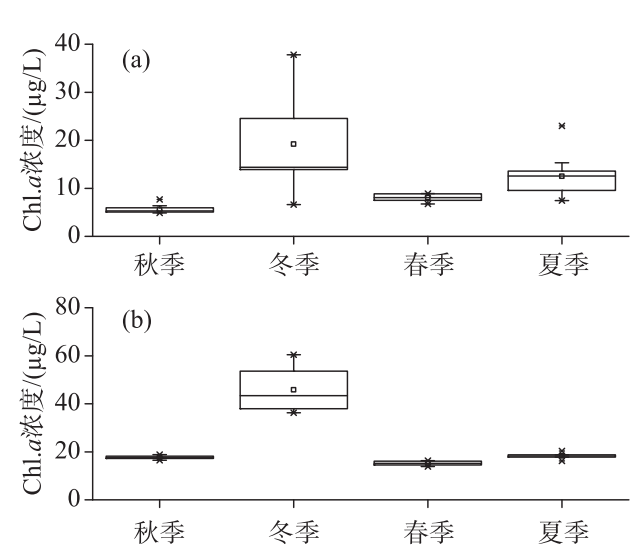

图 5 程海 (a) 和阳宗海 (b) 表层 Chl. $a$ 浓度的季节变化

Fig. 5 Seasonality in chlorophyll- $a$ concentrations of the surface water column in Lake Chenghai (a) and Lake Yangzonghai (b)
宗海冬季的 $\mathrm{TN}$ 和 $\mathrm{NO}_{3}^{-}-\mathrm{N}$ 浓度显著高于秋季、 $\mathrm{SRP}$ 浓度 显著低于秋季, $\mathrm{TN} 、 \mathrm{TP}$ 和 $\mathrm{NO}_{3}^{-}-\mathrm{N}$ 浓度显著高于春季, $\mathrm{NH}_{3}-\mathrm{N}$ 浓度显著低于春季, $\mathrm{TN} 、 \mathrm{NH}_{3}-\mathrm{N}$ 和 $\mathrm{NO}_{3}^{-}-\mathrm{N}$ 浓度显 著高于夏季, TP 浓度显著低于夏季 (表 2). 春季和夏季 比较, 程海除 $\mathrm{TN}$ 浓度 $(P>0.05)$ 外的其他参数均有显著 性差异 $\left(\mathrm{NO}_{3}^{-}-\mathrm{N}, P<0.05\right.$; 其他, $\left.P<0.01\right)$, 阳宗海各参数 均有显著性差异 $(P<0.01)$. 夏季和秋季比较, 程海除 $\mathrm{NH}_{3}-\mathrm{N}$ 浓度 $(P>0.05)$ 外的其他参数均有显著性差异 $(P<0.01)$, 阳宗海的各参数均有显著性差异 $(P<0.01)$.

将四季的表层水体 Chl. $a$ 浓度分别与 WT、SpCond、 $\mathrm{TN} 、 \mathrm{TP} 、 \mathrm{NH}_{3}-\mathrm{N} 、 \mathrm{NO}_{3}-\mathrm{N}$ 和 SRP 浓度进行 Spearman 相关 性检验, 结果 (表 3 ) 显示: 程海的表层水体 Chl. $a$ 浓度与 SpCond、 $\mathrm{TN} 、 \mathrm{NO}_{3}^{-}-\mathrm{N}$ 浓度呈显著正相关; 阳宗海的表层 水体 Chl. $a$ 浓度与 SpCond、 TP 浓度呈显著正相关, 与 $\mathrm{NH}_{3}-\mathrm{N}$ 浓度呈显著负相关. 将相邻季节转化间的表层 Chl. $a$ 浓度分别与 WT、SpCond、TN、TP、 $\mathrm{NH}_{3}-\mathrm{N} 、 \mathrm{NO}_{3}^{-}-\mathrm{N}$ 和 SRP 浓度进行 Spearman 相关性检验, 结果显示 (以 秋一冬季为例, 表 3) : 程海的表层水体 Chl. $a$ 浓度与 SpCond、 $\mathrm{TN} 、 \mathrm{NH}_{3}-\mathrm{N}$ 和 $\mathrm{NO}_{3}^{-}-\mathrm{N}$ 浓度呈显著正相关, 与 WT 呈显著负相关; 阳宗海的表层水体 Chl. $a$ 浓度与 $\mathrm{SpCond} 、 \mathrm{TN}$ 和 $\mathrm{NO}_{3}^{-}-\mathrm{N}$ 浓度呈显著正相关, 与 WT、SRP 浓度呈 显著负相关. 
表 2 程海和阳宗海表层营养盐浓度的季节变化

Tab.2 Seasonality in nutrient concentrations of the surface water column in Lake Chenghai and Lake Yangzonghai

\begin{tabular}{|c|c|c|c|c|c|c|}
\hline \multirow{2}{*}{ 湖泊 } & \multirow{2}{*}{ 季节 } & \multicolumn{5}{|c|}{ 参数 (均值 \pm 标准差) } \\
\hline & & $\mathrm{TN} /(\mathrm{mg} / \mathrm{L})$ & $\mathrm{TP} /\left(\times 10^{-1} \mathrm{mg} / \mathrm{L}\right)$ & $\mathrm{NH}_{3}-\mathrm{N} /(\mathrm{mg} / \mathrm{L})$ & $\mathrm{NO}_{3}^{-}-\mathrm{N} /(\mathrm{mg} / \mathrm{L})$ & $\mathrm{SRP} /\left(\times 10^{-1} \mathrm{mg} / \mathrm{L}\right)$ \\
\hline \multirow[t]{4}{*}{ 程海 } & 秋季 ${ }^{\mathrm{a}}$ & $0.52 \pm 0.03^{* *}$ & $0.58 \pm 0.02$ & $0.03 \pm 0.02 * *$ & $0.46 \pm 0.01^{* * *}$ & $0.06 \pm 0.01$ \\
\hline & 冬季 ${ }^{a}$ & $0.77 \pm 0.07$ & $0.62 \pm 0.06$ & $0.21 \pm 0.06$ & $0.51 \pm 0.01$ & $0.06 \pm 0.02$ \\
\hline & 春季 $^{a}$ & $0.77 \pm 0.07$ & $0.56 \pm 0.03 *$ & $0.24 \pm 0.11$ & $0.51 \pm 0.01$ & $0.04 \pm 0.02 *$ \\
\hline & 夏季 ${ }^{a}$ & $0.74 \pm 0.04$ & $0.15 \pm 0.03^{* *}$ & $0.03 \pm 0.01^{* *}$ & $0.70 \pm 0.03^{* * *}$ & $0.03 \pm 0.01$ ** \\
\hline \multirow[t]{4}{*}{ 阳宗海 } & 秋季 ${ }^{b}$ & $0.43 \pm 0.04^{* *}$ & $0.70 \pm 0.06$ & $0.13 \pm 0.02$ & $0.26 \pm 0.00^{* *}$ & $0.20 \pm 0.03^{\text {** }}$ \\
\hline & 冬季 ${ }^{b}$ & $0.65 \pm 0.09$ & $0.93 \pm 0.60$ & $0.13 \pm 0.04$ & $0.47 \pm 0.03$ & $0.06 \pm 0.02$ \\
\hline & 春季 ${ }^{b}$ & $0.49 \pm 0.16^{*}$ & $0.47 \pm 0.03$ ** & $0.28 \pm 0.05^{* *}$ & $0.30 \pm 0.02 * *$ & $0.07 \pm 0.01$ \\
\hline & 夏季 ${ }^{b}$ & $0.21 \pm 0.04^{* *}$ & $1.57 \pm 0.09^{* *}$ & $0.05 \pm 0.03^{* *}$ & $0.13 \pm 0.01^{* * *}$ & $0.04 \pm 0.01$ \\
\hline
\end{tabular}

${ }^{\mathrm{a}} N=9,{ }^{\mathrm{b}} N=6$; 以冬季为参照, $* P<0.05, * * P<0.01$.

表 3 四季及季节转化期程海和阳宗海表层 Chl. $a$ 浓度与有关参数的 Spearman 相关性

Tab.3 Spearman correlations between chlorophyll- $a$ concentration and physical-chemical parameters in the four seasons and two adjacent seasons (season changes) in Lake Chenghai and Lake Yangzonghai

\begin{tabular}{ccccccccc}
\hline \multirow{2}{*}{ 湖泊 } & 季节 & \multicolumn{7}{c}{ 相关系数 } \\
\cline { 3 - 9 } & & $\mathrm{WT}$ & $\mathrm{S}$ Cond & $\mathrm{TN}$ & $\mathrm{TP}$ & $\mathrm{NH}_{3}-\mathrm{N}$ & $\mathrm{NO}_{3}^{-}-\mathrm{N}$ & $\mathrm{SRP}$ \\
\hline \multirow{2}{*}{ 程海 } & 四季 & -0.221 & $0.607^{* *}$ & $0.535^{* *}$ & -0.266 & 0.276 & $0.502^{* *}$ & -0.191 \\
& 秋一冬 & $-0.755^{* *}$ & $0.832^{* *}$ & $0.612^{* *}$ & 0.085 & $0.767^{* *}$ & $0.638^{* *}$ & 0.186 \\
& 冬一春 & $-0.513^{*}$ & $0.707^{* *}$ & 0.085 & 0.191 & 0.010 & -0.345 & 0.144 \\
& 春一夏 & $0.503^{*}$ & $0.730^{* *}$ & 0.134 & $-0.574^{*}$ & $-0.535^{*}$ & $0.512^{*}$ & -0.335 \\
\multirow{3}{*}{ 阳宗海 } & 四季 & -0.307 & $0.525^{*}$ & 0.270 & $0.548^{* *}$ & $-0.485^{*}$ & $0.255^{*}$ & -0.174 \\
& 秋一冬 & $-0.673^{*}$ & $0.883^{* *}$ & $0.649^{*}$ & 0.054 & -0.270 & $0.708^{* *}$ & $-0.676^{*}$ \\
& 冬一春 & $-0.615^{*}$ & $0.743^{* *}$ & 0.358 & $0.760^{* *}$ & $-0.692^{*}$ & 0.573 & -0.071 \\
& 春一夏 & $0.804^{* *}$ & $-0.777^{* *}$ & $-0.698^{*}$ & $0.816^{*}$ & $-0.594^{*}$ & $-0.797^{* *}$ & $-0.680^{*}$ \\
\hline
\end{tabular}

$* P<0.05, * * P<0.01$.

\section{3 讨论}

在大尺度空间或长序列时间视野下, 湖泊热力分层常受地理位置、湖泊形态、风区长度、辐射、水色及气 候变化等因子的影响. 如, 虽然高山和亚高山湖泊的平均混合层深度可能相近, 但二者的热力结构仍然有差 异 ${ }^{[33]}$; 针对全球 26 个湖泊 $(1970-2010$ 年) 的研究表明热力分层对气候变化的响应与湖泊形态和平均温度 有关 ${ }^{[34]}$; 针对 Lake Pääjärvi 和 Lake Valkea-Mustajärvi 的模拟结果表明,大湖的热力分层更易受风速影响,而 小湖更易受辐射或漫射衰减系数的影响 ${ }^{[35]}$; Woolway 和 Merchant 认为在未来气候变化背景下诸多湖泊的混 合作用会频繁降低 ${ }^{[14]}$. 就温跃层深度而言, 本文基于文献 [35]中 31 个湖泊数据的进一步分析表明温跃层 深度与湖泊最大水深具有较好的正向线性关系 $\left(R^{2}=0.559\right)$; 针对北温带 6 个小湖泊的研究表明, 水色是影 响湖泊热力分层的重要因子, 清澈型湖泊的湖上层较深 ${ }^{[36]}$; 基于千岛湖历史监测数据的研究表明,气候变暖 (分层稳定期表层水温升高) 和透明度降低使温跃层变浅变厚 ${ }^{[10]}$. 横向比较方面,程海和阳宗海的温跃层深 度均较本区域海拔和气象条件相近的抚仙湖浅 ${ }^{[16]}$, 或与两湖的最大风区长度 (或湖区面积) 均小于抚仙 湖 $^{[37]}$ 、水深和真光层深度均浅于抚仙湖 (最大水深为 $155.0 \mathrm{~m}$, 同期四季真光层深度为 $14.85 \pm 4.54 \mathrm{~m}$ ) ${ }^{[38]}$ 有 关; 类似地, 虽然程海与阳宗海的表层水温、真光层深度并无显著性差异, 但程海温跃层的总体位置较阳宗 海更深, 或与程海的湖区面积和水深均大于阳宗海有关. 风场对湖泊分层尤其是混合层深度具有重要影 响 ${ }^{[39]}$, 不同湖泊的混合层深度随风力的增强而增加. 本研究中, 虽然程海和阳宗海的热力分层均存在一定 
的季节变化, 但其四季的混合层深度 (分层期以温跃层深度界定, 程海最小值为 $10.25 \mathrm{~m}$, 阳宗海最小值为 $7.33 \mathrm{~m})$ 普遍较深, 与两湖的有关文献结果接近 ${ }^{[21-22]}$, 而针对抚仙湖和沾沽湖的研究表明其分层期温跃层深 度的最小值大于 $10 \mathrm{~m}^{[16,18]}$; 这 4 个云南湖泊的最小值均大于长江中下游的千岛湖和天目湖 ${ }^{[9,10,13]}$, 而云南 高原的风力强度总体大于长江中下游平原可能是其原因之一. 以阳宗海和千岛湖为例, 根据国家气象信息 中心资料, 1981- 2010 年云南宜良站 (代表阳宗海) 1 月、 4 月、7 月和 10 月的累年月平均风速分别为 2.0 、 $3.1 、 1.8$ 和 $1.5 \mathrm{~m} / \mathrm{s}$, 累年月日最大风速 $\geqslant 5.0 \mathrm{~m} / \mathrm{s}$ 日数分别为 $25.6 、 28.5 、 21.1$ 和 $17.5 \mathrm{~d}$; 浙江淳安站 (台站编 号:58543; 代表千岛湖) 1 月、 4 月、7 月和 10 月的累年月平均风速分别为 $1.7 、 1.6 、 1.7$ 和 $1.7 \mathrm{~m} / \mathrm{s}$, 累年月日最 大风速 $\geqslant 5.0 \mathrm{~m} / \mathrm{s}$ 日数分别为 $7.2 、 8.9 、 12.8$ 和 $5.4 \mathrm{~d}$.

同一湖库热力分层的季节性变化常与辐射、气温、水温、透明度 (真光层深度) 等涉及水体热量收支的因 素有关. 如,太阳辐射被认为是天目湖热力分层变化的主控因子 ${ }^{[13]}$, 太阳辐射和气温变化对沾沽湖热力分 层季节变化具有重要影响 ${ }^{[18]}$; 针对千岛湖的研究表明透明度和表层水温是千岛湖温跃层深度变化的重要影 响因子, 其温跃层深度与透明度呈显著正相关、与表层水温呈显著负相关 ${ }^{[9]}$. 程海和阳宗海的表层水温与气 温的季节变化趋势一致,与总辐射的变化趋势 (两湖所在区域表现出春季最高、夏季次之、冬季最低的趋 势 $)^{[40]}$ 并不完全一致,而两湖热力分层的季节变化表现出了总体一致性与微弱异质性: 秋季至冬季, 随着太 阳辐射减弱、气温降低, 水体释放热量, 两湖温跃层均消退; 冬季至春季, 随着太阳辐射与气温升高, 表层水 温升高, 表底层温差增加, 两湖均开始出现分层现象; 春季至夏季, 随着气温升至最高, 表底层温差达到最 大, 使温跃层上移、变厚 (程海的温跃层强度变强) ; 夏季至秋季, 随着太阳辐射和气温降低, 阳宗海的温跃层 下移、变薄, 但程海的温跃层深度、厚度和强度均未表现出明显变化 (可能是因为程海夏秋季的表层水温接 近). 由此可见, 程海和阳宗海的热力分层均呈现出冬季混合、春季形成分层、夏秋季分层稳定的特征, 且未 观测到明显的逆温层, 说明两湖均属暖单次混合型湖泊 ${ }^{[37]}$. 透明度与真光层深度均可表征水体透光性, 透 明度 (真光层深度) 低, 表层水体获取的太阳能多、水温高, 表层与深层水的温差大, 因而透明度降低会使温 跃层深度变浅厚度变大 ${ }^{[10]}$ 、清澈型湖泊的湖上层较浑浊型湖泊更深 ${ }^{[36]}$. 本研究中, 两湖的分析结果暗示其 真光层深度的单一变化总体上不足以对温跃层深度等参数产生显著影响; 当然, 这可能与本研究所获取的 数据量较少有关, 故而并不排除真光层深度或透明度及其与其他因子的联合作用对水体热力分层的影响.

DO 是反映水体新陈代谢状况的重要指标, 其浓度常受制于大气溶解与 (浮游) 植物光合作用放氧、水生 生物呼吸与有机物降解耗氧等过程的平衡 ${ }^{[37]}$. 热力分层期间, 温跃层阻碍了湖上层 DO 向下扩散, 加之湖下 层的呼吸分解作用, 使湖下层 DO 浓度减小至缺氧甚至厌氧状态, 这在程海和阳宗海热力分层期, 尤其在稳 定分层的夏秋季表现尤为明显. SpCond 可间接表征水体中溶解盐的含量, 其值越高表明溶解盐含量越高. 稳定热力分层期 (夏秋季), 程海和阳宗海的 SpCond 在温跃层附近均呈现出沿水深升高的趋势, 这与淡水贫 营养的泸沽湖 ${ }^{[18]}$ 不同, 而与贫中营养的龙滩水库 ${ }^{[41]}$ 、中营养的天山天池 ${ }^{[11]}$ 一致; 换言之, 作为中营养湖泊, 程海和阳宗海夏秋季湖下层的溶解盐含量总体较湖上层高, 可能与湖下层较强的分解 (矿化) 作用有关, 而 关于夏季程海温跃层的 SpCond 随水深先升高后下降的现象则有待进一步研究. 当秋季转为冬季时, 两湖真 光层的 SpCond 均明显升高、底层的 SpCond 则明显下降, 说明随着热力分层的消退, 底层的溶解盐可随水体 上下层的混合而向表层输送. 加之期间的降水量较少且呈减少趋势, 意味着大气沉降与河流输人的营养盐 有限, 暗示热力分层消退可能是导致表层无机营养盐 (如氨氮及富氧条件下经硝化作用产生的硝酸盐氮, 亦 可能有磷) 升高的重要原因 (表 2). 当冬季转春季时, 降水量微弱的升高或不能带来流域营养物质的大量人 湖, 而可能对水体溶解盐起到一定的稀释作用, 进而成为两湖表层及水柱 SpCond 呈降低趋势的原因之一; 从春季的剖面来看, SpCond 随水深的增加有微弱的上升趋势, 意味着热力分层的初步形成已利于底层溶解 盐含量的升高.

浮游植物的生长和生物量常直接受制于藻类自身及光照、温度和营养盐的综合作用, 且主控因子具有 季节性或阶段性特征 ${ }^{[42]}$, 如孔繁翔和高光 ${ }^{[43]}$ 针对长江中下游湖泊提出的 “蓝藻水华成因的四阶段理论假 设”正说明了这点. 无论四季还是季节转化的分析均显示两湖的 Chl. $a$ 浓度与 SpCond 基本呈显著的正相关 ( 阳宗海非连续的春夏季除外, 表 3), 说明溶解盐含量在两湖浮游植物生物量的变化方面总体上发挥了重要 的正向作用,但不同类别和形态营养盐的影响作用同样具有湖泊和季节间异质性. 本研究中的秋季转冬季 
时, 虽然两湖的总辐射 ${ }^{[40]}$ 和表层水温均降至年度最低, 但期间的光照 (程海和阳宗海冬季的真光层深度分 别为 $6.09 \pm 0.47$ 和 $6.22 \pm 0.74 \mathrm{~m}$ ) 和温度 (程海和阳宗海冬季的表层水温分别为 $14.33 \pm 0.12$ 和 $13.63 \pm 0.16^{\circ} \mathrm{C}$ ) 条件仍能满足浮游植物的生长, 如 $\mathrm{Ma}$ 等 $^{[44]}$ 的研究显示当温度 $\geqslant 12.5^{\circ} \mathrm{C}$ 时太湖冬季的微囊藻能继续生长; 由 于热力分层消退导致水体表层无机营养盐的显著升高, 可能是支撑浮游植物生长和年度最高生物量的物质 基础（表 3 ); 而两湖冬季的表层水体 Chl. $a$ 浓度变化幅度均较其他季节更大 (图 5), 可能与不同点位的水深

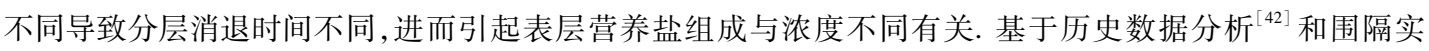
验 ${ }^{[45]}$ 的结果推断, 云南滇池的浮游植物在旱季 (春季) 存在光抑制作用. 本研究中, 冬季转春季时, 虽然两湖 的表层水温升高、总辐射由最低升至最高 ${ }^{[40]}$, 但除了阳宗海的氨氮外并未检测到 Chl. $a$ 浓度与其他溶解性 营养盐间显著的相关关系, 暗示两湖浮游植物在春季可能存在光抑制作用, 进而成为两湖浮游植物生物量 明显下降的原因之一; 阳宗海浮游植物生物量的降低可能还与 TP 浓度显著降低, 以及 $\mathrm{NH}_{3}-\mathrm{N}$ 浓度显著升高 对藻类产生毒性 ${ }^{[46]}$ 有关 (表 2 和表 3 ). 春季转夏季时, 程海和阳宗海浮游植物生物量的显著升高不仅与已 被普遍接受的表层水温升高更利于浮游植物生长 (表 3)、形成稳定的热力分层阻碍上下层物质交换有 关 ${ }^{[24-25]}$, 我们推测可能还与光抑制作用减弱甚至消失、 $\mathrm{NH}_{3}-\mathrm{N}$ 浓度降低导致其对藻类的毒性降低有关, 此外 阳宗海 Chl. $a$ 浓度升高还与 TP 浓度的升高有关 (表 2 和表 3 ); 期间, 两湖 Chl. $a$ 浓度与 $\mathrm{NO}_{3}^{-}-\mathrm{N}$ 浓度的相关 性表现出了不同, 程海的正向关系可能是因为水体的补充速率大于藻类的吸收速率 (春季至夏季, 水体 $\mathrm{NO}_{3}^{-}-\mathrm{N}$ 浓度显著升高, $P<0.01$ ), 阳宗海的负向关系可能是因为藻类的吸收速率大于水体的补充速率 (春季 至夏季, 水体硝酸盐氮浓度显著降低, $P<0.01)$, 阳宗海在溶解性活性磷与 Chl. $a$ 浓度的关系方面亦有所体现 (秋季至冬季、春季至夏季). 根据临界层理论 ${ }^{[47]}$, 程海和阳宗海的真光层深度均明显小于混合层深度而不 易发生藻类水华; 然而, 当扰动混合速率低于临界扰动时亦可能发生藻类水华 ${ }^{[48]}$, 两湖 (冬季) 藻类水华的 发生或属于此种情况.

需指出的是, 本研究主要是基于程海和阳宗海水体分层和浮游植物生物量季节变化特征的初步分析与 推断, 而缺乏针对周年热力分层转化及其关键时期的水动力、剖面营养盐及浮游植物等数据的长期高频观 测, 故只是在初步认识两湖水体分层特征的基础上, 提供了一种针对浮游植物生物量季节变化, 尤其冬季水 华发生的案例和可能解释. 而在未来复杂的气候变化与人为干扰背景下, 为了更加全面深人地认识程海和 阳宗海及本区域其他类似湖泊的水体热力分层特征及其生态环境效应 (如, 揭示其对浮游植物群落结构变 化乃至水华发生的驱动机制等),仍有大量的系统工作需要且值得开展.

\section{4 结论}

程海和阳宗海水体分层的特征均为冬季混合、春季形成分层、夏秋季分层稳定, 均属暖单次混合型湖 泊, 程海温跃层的总体位置较阳宗海更深. 热力分层稳定期, 两湖水柱底层形成缺氧甚至厌氧条件, 底层电 导率总体较表层高; 秋季转冬季热力分层消退可能是导致水体表层无机营养盐升高的重要原因, 加之适宜 的光热条件可诱导两湖冬季表层水华的发生 (不排除浮游植物垂向迁移的可能贡献); 冬季转春季总辐射升 至年度最高可能对浮游植物产生光抑制作用, 加之两湖电导率 (溶解盐浓度) 降低及 (阳宗海) TP 浓度的降 低或 $\mathrm{NH}_{3}-\mathrm{N}$ 浓度的升高 (或有毒性作用), 进而使浮游植物生物量降低; 春季转夏季, 两湖浮游植物生物量 的升高不仅与水温升高有关, 可能还与辐射降低 (光抑制作用减弱) 及水柱表层营养盐组分的变化有关. 关 于云南乃至云贵高原深水湖泊热力分层特征及其生态环境效应, 尤其是对浮游植物群落变化及水华发生影 响等的研究,仍有大量的系统性甚至基础性的工作需要开展.

致谢: 感谢陈毅良、孔德平、聂菊芬等协助的现场调查或样品分析工作,感谢张运林研究员的帮助!

\section{5 参考文献}

[ 1 ] Zhang Y, Wu Z, Liu M et al. Dissolved oxygen stratification and response to thermal structure and long-term climate change in a large and deep subtropical reservoir (Lake Qiandaohu, China). Water Research, 2015, 75: 249-258. DOI: 10.1016/j.watres.2015.02.052.

[ 2 ] Fuchs A, Klier J, Pinto F et al. Effects of artificial thermocline deepening on sedimentation rates and microbial processes 
in the sediment. Hydrobiologia, 2017, 799( 1) : 65-81. DOI: 10.1007/s10750-017-3202-7.

[ 3 ] Selmeczy GB, Krienitz L, Casper P et al. Phytoplankton response to experimental thermocline deepening: A mesocosm experiment. Hydrobiologia , 2018, 805(1) : 259-271. DOI: 10.1007/s10750-017-3308-y.

[ 4 ] Kirf M, Røy H, Holtappels M et al. Redox gradients at the low oxygen boundary of lakes. Aquatic Sciences, 2015, 77 (1) : 81-93. DOI: 10.1007/s00027-014-0365-4.

[ 5 ] Mellard JP, Yoshiyama K, Litchman E et al. The vertical distribution of phytoplankton in stratified water columns. Journal of Theoretical Biology, 2011, 269(1) : 16-30. DOI: 10.1016/j.jtbi.2010.09.041.

[6] Ryabov AB, Rudolf L, Blasius B. Vertical distribution and composition of phytoplankton under the influence of an upper mixed layer. Journal of Theoretical Biology, 2010, 263(1) : 120-133. DOI: 10.1016/j.jtbi.2009.10.034.

[ 7 ] Wilhelm S, Adrian R. Impact of summer warming on the thermal characteristics of a polymictic lake and consequences for oxygen, nutrients and phytoplankton. Freshwater Biology, 2008, 53 (2) : 226-237. DOI: 10.1111/j.1365-2427.2007. 01887.x.

[ 8 ] Flaim G, Eccel E, Zeileis A et al. Effects of re-oligotrophication and climate change on lake thermal structure. Freshwater Biology, 2016, 61(10) : 1802-1814. DOI: 10.1111/fwb.12819.

[ 9 ] Liu ML, Wu ZX, He JB et al. Thermodynamics and stratification in Xin'anjiang Reservoir (Lake Qiandao). J Lake Sci, 2014, 26(3) : 447-454. DOI: 10.18307/2014.0316. [刘明亮, 吴志旭, 何剑波等. 新安江水库(千岛湖) 热力学状 况及热力分层研究. 湖泊科学, 2014, 26(3): 447-454.]

[10] Zhang Y, Wu Z, Liu M et al. Thermal structure and response to long-term climatic changes in Lake Qiandaohu, a deep subtropical reservoir in China. Limnology and Oceanography, 2014, 59(4) : 1193-1202. DOI: 10.4319/lo. 2014.59. 4.1193.

[11] Wang B, Ma J, Wang YY et al. Seasonal characteristics of thermal stratification in Lake Tianchi of Tianshan Mountains. $J$ Lake Sci, 2015, 27(6) : 1197-1204. DOI: 10.18307/2015.0626. [王斌, 马健, 王银亚等. 天山天池水体季节性分层 特征. 湖泊科学, 2015, 27(6): 1197-1204.]

[12] Huang L, Wang JB, Zhu LP et al. Water temperature and characteristics of thermal stratification in Nam Co, Tibet. J Lake $S c i, 2015,27$ (4) : 711-718. DOI: 10.18307/2015.0420. [黄磊, 王君波, 朱立平等. 纳木错水温变化及热力学分层 特征初步研究. 湖泊科学, 2015, 27(4): 711-718.]

[13] Sun X, Zhu GW, Da WY et al. Thermal stratification and its impacts on water quality in Shahe Reservoir, Liyang, China. Environmental Science, 2018, 39(6) : 2632-2640. DOI: 10.13227/j.hjkx.201710223. [孙祥, 朱广伟, 笪文怡等. 天目 湖沙河水库热分层变化及其对水质的影响. 环境科学, 2018, 39(6) : 2632-2640.]

[14] Woolway RI, Merchant CJ. Worldwide alteration of lake mixing regimes in response to climate change. Nature Geoscience, 2019, 12(4) : 271-276. DOI: 10.1038/s41561-019-0322-x.

[15] Woolway RI, Merchant CJ. Intralake heterogeneity of thermal responses to climate change: a study of large Northern Hemisphere lakes. Journal of Geophysical Research: Atmospheres, 2018, 123(6) : 3087-3098. DOI: 10.1002/2017JD027661.

[16] Fu ZH. Research on the thermocline in Fuxian Lake. Transactions of Oceanology and Limnology, 2015, (1): 9-12. [付朝 晖. 抚仙湖水温跃层研究. 海洋湖沼通报, 2015, (1):9-12.]

[17] Wang YZ, Pu PM. Preliminary study on the thermocline in Fuxian Lake. Transactions of Oceanology and Limnology, 1982, (4) : 1-9. [王银珠, 﨔培民. 抚仙湖水温跃层的初步研究. 海洋湖沼通报, 1982, (4) : 1-9.]

[18] Wen XY, Zhang HC, Chang FQ et al. Seasonal stratification characteristics of vertical profiles of water body in Lake Lugu. Advances in Earth Science, 2016, 31(8): 858-869. [文新宇, 张虎才, 常凤琴等. 沾沽湖水体垂直断面季节性分层. 地球科学进展, 2016, 31(8): 858-869.]

[19] Zhao XF. Seasonal variations of thermal stratification and its environmental effects in Lake Lugu [Dissertation]. Guangzhou: Jinan University, 2014. [赵雪枫, 沾沽湖温度分层季节变化及其环境效应 [ 学位论文]. 广州: 暨南大 学, 2014.]

[20] Zhao QH, Sun JH. The variation features of the surface mixed layer depth in Erhai Lake and Taihu Lake in spring and autumn and their mechanism analyses. Acta Physica Sinica, 2013, 62(3) : 039203. DOI: 10.7498/aps.62.039203. [赵巧 华, 孙绩华. 夏秋两季洱海、太湖表层混合层的深度变化特征及其机理分析. 物理学报, 2013, 62(3): 039203.]

[21] Lu ZM, Zhang HC, Chang FQ et al. Seasonal variation and spatial heterogeneity of water quality parameter in Chenghai. Geographical Science Research, 2017, 6(3) : 157-167. DOI : 10.12677/gser.2017.63018. [路志明, 张虎才, 常凤琴等. 
程海水质参数季节变化特征与空间异质性. 地理科学研究, 2017, 6(3) : 157-167.]

[22] Yuan LN, Yang CL, Li XM et al. Effect of daily thermal stratification on dissolved oxygen, $\mathrm{pH}$, total phosphorus concentration, phytoplankton and algae density of a deep plateau lake: A case study of Lake Yangzonghai, Yunnan Province. $J$ Lake Sci, 2014, 26(1) : 161-168. DOI: 10.18307/2014.0120. [袁琳娜, 杨常亮, 李晓铭等. 高原深水湖泊水温日成 层对溶解氧、酸碱度、总磷浓度和藻类密度的影响: 以云南阳宗海为例. 湖泊科学, 2014, 26(1): 161-168.]

[23] Zhang M, Zhang Y, Yang Z et al. Spatial and seasonal shifts in bloom-forming cyanobacteria in Lake Chaohu: patterns and driving factors. Phycological Research, 2016, 64(1) : 44-55. DOI: 10.1111/pre.12112.

[24] Paerl HW, Otten TG, Kudela R. Mitigating the expansion of harmful algal blooms across the freshwater-to-marine continuum. Environmental Science \& Technology, 2018, 52(10) : 5519-5529. DOI : 10.1021/acs.est.7b05950.

[25] Huisman J, Codd JA, Paerl HW et al. Cyanobacterial blooms. Nature Reviews Microbiology, 2018, 16: 471-483. DOI: 10.1038/s41579-018-0040-1.

[26] Posch T, Koster O, Salcher MM et al. Harmful filamentous cyanobacteria favoured by reduced water turnover with lake warming. Nature Climate Change, 2012, 2(11) : 809-813. DOI: 10.1038/nclimate1581.

[27] Huang LC, Zhou YY, Zhou QC et al. Temporal-spatial variation in phytoplankton primary production and its influencing factors in Lake Chenghai on the Yunnan Plateau, China. J Lake Sci, 2019, 31 (5) : 1424-1436. DOI: 10.18307/2019. 0508. [黄立成, 周远洋, 周起超等. 云南程海浮游植物初级生产力的时空变化及其影响因子. 湖泊科学, 2019, 31(5): 1424-1436.]

[28] Dong YX, Tan ZW, Zhu X et al. Annual variation of phytoplankton community structure and change of the number in Chenghai Lake. Ecology and Environmental Sciences, 2012, 21(7)：1289-1295. [董云仙, 谭志卫, 朱翔等. 程海藻类 植物种群结构和数量的周年变化特征. 生态环境学报, 2012, 21(7) : 1289-1295.]

[29] Dong YX, Hong XH, Hu JQ et al. The N and P chemical speciation and temporal-spatial pattern during a winter bloom event in Lake Chenghai, China. Ecology and Environmental Sciences, 2010, 19(11): 2675-2679. [董云仙, 洪雪花, 胡 锦乾等. 程海冬季水华暴发期间氮、磷营养元素的形态与分布. 生态环境学报, 2010, 19(11): 2675-2679.]

[30] Li CY, Yang ZL. Evaluation of phytoplankton communities and trophic states in Lake Yangzonghai. Pearl River, 2013,34 (3) : 20-23. [李春永，杨中兰. 阳宗海浮游植物群落与营养状态评价. 人民珠江, 2013, 34(3) : 20-23.]

[31] Kirk JTO ed. Light and photosynthesis in aquatic ecosystems: 3rd ed. New York: Cambridge University Press, 2011.

[32] Editorial board of "monitoring and analysis methods of water and wastewater" of the Ministry of Environmental Protection of the People's Republic of China ed. Monitoring and analysis methods of water and wastewater: 4th edition. Beijing: China Environmental Science Press, 2002. [国家环境保护总局《水和废水监测分析方法》编委会. 水和废水监测分析方 法: 第 4 版. 北京: 中国环境科学出版社, 2002.]

[33] Rose KC, Williamson CE, Saros JE et al. Differences in UV transparency and thermal structure between alpine and subalpine lakes: implications for organisms. Photochemical and Photobiological Sciences, 2009, 8(9) : 1244-1256. DOI: 10. 1039/B905616E.

[34] Kraemer BM, Anneville O, Chandra S et al. Morphometry and average temperature affect lake stratification responses to climate change. Geophysical Research Letters, 2015, 42(12) : 2015GL064097. DOI: 10.1002/2015GL064097.

[35] Virta J, Elo AR. The effects of basin dimensions on the seasonal depth of thermocline and temperature of hypolimnion in small lakes. Geophysica, 2011, 47(1/2): 69-93.

[36] Houser JN. Water color affects the stratification, surface temperature, heat content, and mean epilimnetic irradiance of small lakes. Canadian Journal of Fisheries and Aquatic Sciences, 2006, 63(11) : 2447-2455. DOI: 10.1139/f06-131.

[37] Kalff J ed. Limnology: Inland water ecosystems. New Jersey: Prentice Hall, 2002.

[38 ] Zhou Q, Zhang Y, Li K et al. Seasonal and spatial distributions of euphotic zone and long-term variations in water transparency in a clear oligotrophic Lake Fuxian, China. Journal of Environmental Sciences, 2018, 72: 185-197. DOI: 10.1016/j. jes.2018.01.005.

[39] MacIntyre S, Crowe AT, Cortés A et al. Turbulence in a small arctic pond. Limnology and Oceanography, 2018, 63(6) : 2337-2358. DOI: 10.1002/lno.10941.

[40] Wang XF, Zhu Y, Fan LZ et al. Spatial-temporal variations of solar global radiation in Yunnan Province during 19612007. Advances in Climate Change Research, 2009, 5(1): 29-34. [王学锋, 朱勇, 范立张等. 1961-2007 年云南太 阳总辐射时空变化特征. 气候变化研究进展, 2009, 5(1): 29-34.] 
[41] Zhang L, Li QH, Huang GJ et al. Seasonal stratification and eutrophication characteristics of a deep reservoir, Longtan Reservoir in subtropical area of China. Environmental Science, 2015, 36(2) : 438-447. DOI: 10.13227/j.hjkx.2015.02. 010. [张垒, 李秋华, 黄国佳等. 亚热带深水水库一一龙滩水库季节性分层与富营养化特征分析. 环境科学, $2015,36(2): 438-447$.

[42] Zhou Q, Zhang Y, Lin D et al. The relationships of meteorological factors and nutrient levels with phytoplankton biomass in a shallow eutrophic lake dominated by cyanobacteria, Lake Dianchi from 1991 to 2013. Environmental Science and Pollution Research, 2016, 23(15) : 15616-15626. DOI: 10.1007/s11356-016-6748-4.

[43] Kong FX, Gao G. Hypothesis on cyanobacteria bloom-forming mechanism in large shallow eutrophic lakes. Acta Ecologica Sinica, 2005, 25(3) : 589-595. [ 孔繁翔, 高光. 大型浅水富营养化湖泊中蓝藻水华形成机理的思考. 生态学报, $2005,25(3): 589-595$. ]

[44] Ma J, Qin B, Paerl HW et al. The persistence of cyanobacterial (Microcystis spp.) blooms throughout winter in Lake Taihu, China. Limnology and Oceanography, 2016, 61(2) : 711-722. DOI: 10.1002/lno.10246.

[45] Zhou QC, Song LR, Li L. Effect of shading on the algal blooms during spring in Lake Dianchi. Environmental Science \& Technology, 2015, 38(9) : 53-59. [周起超, 宋立荣, 李林. 遮光对滇池春季藻类水华的影响. 环境科学与技术, $2015, \mathbf{3 8}(9)$ : 53-59.]

[46] Dai GZ, Shang JL, Qiu BS. Ammonia may play an important role in the succession of cyanobacterial blooms and the distribution of common algal species in shallow freshwater lakes. Global Change Biology, 2012, 18(5) : 1571-1581. DOI: 10. $1111 / \mathrm{j} .1365-2486.2012 .02638 . x$.

[47] Sverdrup HU. On conditions for the vernal blooming of phytoplankton. ICES Journal of Marine Science, 1953, 18(3): 287-295. DOI: 10.1093/icesjms/18.3.287.

[48] Huisman J, van Oostveen P, Weissing FJ. Critical depth and critical turbulence: Two different mechanisms for the development of phytoplankton blooms. Limnology and Oceanography, 1999, 44(7) : 1781-1787. DOI: 10.4319/lo.1999.44. 7.1781 . 